\title{
Planejamento anual e quadrienal de prestação de contas à Capes por meio da ferramenta computacional Scriptsucupira
}

\section{Planning of annual and quadrennial accountability to Capes using Scriptsucupira computational tool}

\section{Planificación anual y cuadrienal de la rendición de cuentas para la Capes con la herramienta Scriptsucupira}

http://dx.doi.org/10.221713/2358-2332.2016.v14.13201

Renato Ribeiro Nogueira Ferraz, doutor em Ciências Básicas pela Universidade Federal de São Paulo (Unifesp), professor do Programa de Pós-Graduação em Administração e do Programa de Mestrado Profissional em Administração - Gestão em Sistemas de Saúde - da Universidade Nove de Julho (Uninove), São Paulo, SP, Brasil. E-mail: renatobio@ hotmail.com.

Emerson Antônio Maccari, doutor em Administração pela Universidade de São Paulo (USP), diretor e professor do Programa de Pós-Graduação em Administração e professor do Mestrado Profissional em Administração - Gestão de Projetos - da Universidade Nove de Julho (Uninove), São Paulo, SP, Brasil. E-mail: emersonmaccari@gmail.com.

Luc Quoniam, doutor em Ciências da Informação e da Comunicação pela Université Aix Marseille III, França, professor e líder do Grupo de Pesquisa Lab4u da Universidade Federal de São Carlos (UFSCar), São Carlos, SP, Brasil. Pesquisador do laboratório IRSIC (EA4262) Aix Marseille Université, Marseille, França. Professor da Université du Sud Toulon-Var, Toulon, França. E-mail: quoniam@mail.info.

Marcus Vinicius Cesso da Silva, mestrando do Programa de Pós-Graduação em Administração da Universidade Nove de Julho (Uninove), São Paulo, SP, Brasil. E-mail: marcus.cesso@gmail.com.

Aline Fátima Modkovski, mestre em Administração pelo Programa de Pós-Graduação em Administração da Universidade Nove de Julho (Uninove), São Paulo, SP, Brasil. E-mail: ale_faz@hotmail.com.

\section{Resumo}

A ferramenta computacional Scriptsucupira é um programa-robô que direciona a extração, da Plataforma Lattes, de informações acadêmicas e profissionais cadastradas nos currículos de pesquisadores vinculados às diversas linhas de pesquisa de um curso de pós-

\footnotetext{
${ }^{1}$ Como citar: ABNT NBR 6023:2002 e incluir o DOI.
} 
Ferraz et al. / Planejamento anual e quadrienal de prestação de contas à Capes por meio da ferramenta computacional Scriptsucupira

graduação stricto sensu. Com base nessas informações, a Scriptsucupira cria relatórios de produção, redes de colaboração em pesquisa e mapas geográficos de investigação. Neste trabalho, utilizou-se o Scriptsucupira para planejar o preenchimento anual e quadrienal da Plataforma Sucupira com base na produção acadêmica de um programa de pós-graduação stricto sensu em Administração. Os resultados dessa experimentação contribuíram sobremaneira para que os gestores do programa avaliado acompanhassem o desempenho individual dos professores, das linhas de pesquisa e dos cursos que compunham o programa, assim possibilitando o desenvolvimento de estratégias para alavancar a produtividade dos pares ainda na vigência do quadriênio 2013-2016.

Palavras-chave: Scriptsucupira. Plataforma Lattes. Plataforma Sucupira. Capes. Inovação.

\section{Abstract}

Scriptsucupira computational tool is a robot program that guides the extraction, from the Lattes Platform, of academic and professional information contained in the curricula of researchers linked to several research lines of graduate programs in specialized fields. Based on such information, Scriptsucupira creates production reports, research collaboration networks, and geographical maps of the research. In this study, Scriptsucupira was used to plan the annual and quadrennial accountability of the Sucupira Platform based on the academic production of a Graduate Program in Business. The results have greatly contributed to the monitoring, by managers of the evaluated Program, of the professors' individual performance, of research lines, and the courses that comprised the Program, enabling the development of strategies to leverage peer productivity in the 2013-2016 quadrennium.

Keywords: Scriptsucupira. Lattes Platform. Sucupira Platform. Capes. Inovação.

\section{Resumen}

La herramienta computacional Scriptsucupira se constituye en un programa robot que dirige la extracción, de la plataforma Lattes, de informaciones académicas y profesionales de los currículos de investigadores vinculados a diversas líneas de investigación de un curso de postgrado stricto sensu. Basándose en estas informaciones, la Scriptsucupira crea informes de producción, redes de colaboración y mapas geográficos de investigación. En este estudio hemos utilizado la Scriptsucupira para planificar el llenado anual y cuatrienal de la plataforma Sucupira basada en la producción académica del programa de postgrado stricto sensu en Administración. Los resultados de este ensayo han contribuido en gran medida al seguimiento por parte de los administradores del programa evaluado, el rendimiento individual del profesor, las líneas de investigación y cursos que componen el programa, lo que permite el desarrollo de estrategias para potenciar la productividad de los pares todavía en la duración del cuadrienio 2013-2016.

Palabras clave: Scriptsucupira. Plataforma Lattes. Plataforma Sucupira. Capes. Inovación. 
Ferraz et al. / Planejamento anual e quadrienal de prestação de contas à Capes por meio da ferramenta computacional Scriptsucupira

\section{INTRODUÇÃO}

Os processos de avaliação dos cursos de pós-graduação podem contribuir para a evolução dos mecanismos educacionais de um país, já que são capazes de fornecer indicadores imparciais sobre os parâmetros qualitativos relacionados ao próprio processo. Um sistema de avaliação, quando bem conduzido, identifica vieses e fornece propostas que auxiliam no cumprimento dos objetivos vinculados às melhorias sugeridas para o setor (ALLEN, 1996). Por muito tempo, tais processos foram utilizados por candidatos à graduação como instrumentos meramente auxiliares na escolha de cursos e universidades que desejavam ingressar (WILLIS, 1992).

A avaliação era utilizada primordialmente para apontar as deficiências nos cursos e, quando possível, propor mudanças, todavia, na maioria das vezes, influenciadas por interesses políticos (ALLEN, 1996; DURHAM, 1990; HOUSE, 1992). A mudança gradativa deste panorama, ocorrida nos últimos 30 anos, vem contribuindo de maneira efetiva para que as diversas reformas educacionais transcorridas no período pudessem ser instituídas (ALLEN, 1996; WALTER et al., 2013).

No Brasil, a partir da metade do século passado, a valorização do conhecimento científico - especialmente aquele associado às novas tecnologias e diretamente atrelada à valorização de profissionais mais capacitados - mostrava a sua importância para o desenvolvimento econômico e social da nação. Porém, no início, o Brasil contava com um número bastante reduzido de alunos matriculados em cursos superiores, comparando-se aos países considerados desenvolvidos, além de praticamente não existirem cursos de pósgraduação.

Com o intuito de minimizar o quadro descrito surgiu a Coordenação de Aperfeiçoamento de Pessoal de Nível Superior (Capes), cuja atribuição principal se baseava em estimular a formação de profissionais gabaritados e em quantidade suficiente para atender as demandas vividas pelo país à época. A partir de então, a Capes tem sido o órgão responsável por estimular a expansão e consolidação de programas de pós-graduação na modalidade stricto sensu no Brasil e, sobretudo, por realizar a avaliação periódica dos referidos cursos visando assegurar a sua qualidade. Para tal, a Capes se mantém em constante processo evolutivo, estimulando o aperfeiçoamento contínuo do seu próprio sistema de avaliação (OLIVEIRA et al., 2008), o qual é reconhecido por sua eficiência e eficácia no tangente à avaliação de programas de stricto sensu (MACCARI et al., 2008).

$\mathrm{Na}$ atualidade, os programas de pós-graduação stricto sensu passam por acompanhamento anual, realizado por meio de levantamento de dados, e por avaliação quadrienal. Ambos os procedimentos são conduzidos pela Capes, mediante a utilização de um software específico, mantido pela própria coordenação, denominado Plataforma Sucupira, que é alimentado pelos próprios gestores dos programas de pós-graduação.

Após o cadastro manual dos dados pessoais, profissionais e acadêmicos de cada docente, discente e egresso, inúmeras informações a respeito da atividade acadêmica são coletadas da Plataforma Lattes e inseridas na Plataforma Sucupira. Esta, disponibilizada no ano de 2014, foi 
Ferraz et al. / Planejamento anual e quadrienal de prestação de contas à Capes por meio da ferramenta computacional Scriptsucupira

assim chamada em homenagem ao professor Newton Sucupira, autor do Parecer $n^{\circ}$ 977, de 1965, que institucionalizou a pós-graduação brasileira nos moldes como é até os dias de hoje.

A Plataforma Sucupira substituiu o Coleta Capes - mecanismo de prestação de contas vigente até a referida data - e passou a oferecer, em tempo real e com mais transparência, as informações dos programas de pós-graduação, que por sua vez servem de referência ao Sistema Nacional de Pós-Graduação (SNPG) (COORDENAÇÃO DE APERFEIÇOAMENTO DE PESSOAL DE NÍVEL SUPERIOR, 2014).

O preenchimento da Plataforma Sucupira demanda atenção, pois qualquer informação que porventura for esquecida ou preenchida de maneira incorreta poderá influenciar negativamente na avaliação final do programa (SCHERER et al., 2012).

A literatura é escassa no tocante a relatos sobre a existência de ferramentas computacionais que auxiliem o preenchimento da Plataforma. Embora haja sistemas internos de algumas bibliotecas cujo intuito é organizar as informações acadêmicas de seus professores, eles não apresentam um grau de compatibilidade de forma a tomá-las como base nem para o preenchimento do antigo Coleta Capes (COSTA, 1996), tampouco para o preenchimento da Sucupira.

Ainda, os poucos sistemas disponíveis não agrupam adequadamente as informações relativas ao desempenho dos professores a ponto de permitir aos gestores dos programas realizar um acompanhamento atualizado da atividade individual de seus docentes, das linhas de pesquisa integrantes de seus cursos ou dos programas sob sua gestão como um todo, especialmente com vistas a desenvolver estratégias que busquem alavancar a produção bibliográfica, técnica e tecnológica de seus pesquisadores no decorrer do ano ou do mesmo quadriênio vigente, evitando assim quaisquer transtornos relacionados ao não cumprimento das metas estabelecidas pela Capes para os cursos de pós-graduação stricto sensu.

Nesse sentido, este trabalho apresenta e propõe a utilização de uma metodologia para extração e tratamento dos dados existentes na Plataforma Lattes, de maneira a organizar e tornar pública e transparente a produção bibliográfica, técnica e tecnológica de um determinado grupo de pesquisadores, bem como suas orientações e projetos de pesquisa finalizados e em curso, dentre outras informações. Pretende-se disponibilizar tais informações de forma que possam ser utilizadas no planejamento anual e quadrienal da alimentação da Plataforma Sucupira, o que, por sua vez, permite aos gestores de cursos stricto sensu realizar o acompanhamento e avaliação da produção acadêmica atualizada de seus programas de maneira automatizada.

A área de Administração Pública e de Empresas, Ciências Contábeis e Turismo representa uma parcela do conhecimento que cada vez mais se consolida e se fortalece nos campos científico, tecnológico e nas áreas voltadas à produção de inovação. A atuação dos profissionais dessa área está presente em basicamente todas as formas de organizações coletivas de caráter público ou privado, tanto empresariais quanto não empresariais. Portanto, para melhor compreensão do propósito descrito, elencamos um caso prático de disponibilização online da produção científica dos pesquisadores vinculados a um programa de pós-graduação stricto sensu em Administração, com base nos dados fornecidos à Plataforma Lattes pelos próprios pesquisadores. 
Ferraz et al. / Planejamento anual e quadrienal de prestação de contas à Capes por meio da ferramenta computacional Scriptsucupira

Para tanto, além desta introdução, discorre-se, no desenvolvimento do artigo, sobre a Capes e o processo de avaliação dos programas de pós-graduação stricto sensu, assim como sobre a Plataforma Lattes, cujos dados se encontram alocados em uma área pouco conhecida da internet, que agrupa uma série de conteúdos de elevado interesse para as diferentes áreas do conhecimento humano (OLIVEIRA; TOTTI; SOUZA, 2013). Em seguida, são apresentadas as principais ferramentas de automatização da extração de informações da Plataforma Lattes. Descreve-se a ferramenta computacional Scriptsucupira, cuja aplicação é o foco central desta pesquisa. A seção de Método apresenta os mecanismos computacionais básicos com os quais a ferramenta Scriptsucupira trabalha, bem como a abordagem metodológica de condução deste trabalho. Na seção de Resultados são apresentadas, de maneira sequencial, as diferentes páginas da web geradas e disponibilizadas após a realização do tratamento dos currículos dos pesquisadores do programa de pós-graduação avaliado. A seção de Considerações Finais discorre sobre a aplicabilidade dos resultados demonstrados e ratifica a importância de tornar públicos os resultados de pesquisas científicas para identificação do retorno que estas fornecem à sociedade, por meio da divulgação dos produtos, processos e técnicas desenvolvidos pelos pesquisadores listados (caracterizando o nível de responsabilidade social da pesquisa), e sobre a importância da realização de análises prospectivas dos resultados das pesquisas em andamento (o que se conhece como estudos de forecasting), já que permite acompanhar todas as orientações de dissertações e teses vigentes realizadas pelos pesquisadores, além de suas supervisões de pós-doutorado e seus projetos de pesquisa em desenvolvimento.

\section{CAPES, PLATAFORMA LATTES, PLATAFORMA SUCUPIRA E SCRIPTSUCUPIRA}

\subsection{A Capes e o sistema de avaliação da pós-graduação stricto sensu}

A Capes foi criada em 11 de julho de 1951 pelo Decreto $\mathrm{n}^{\circ} 29.741$, sendo, naquela época, denominada Campanha Nacional de Aperfeiçoamento de Pessoal de Nível Superior, com o objetivo de "assegurar a existência de pessoal especializado em quantidade e qualidade suficientes para atender às necessidades dos empreendimentos públicos e privados que visam ao desenvolvimento do país" (COORDENAÇÃO DE APERFEIÇOAMENTO DE PESSOAL DE NÍVEL SUPERIOR, 2008). Com o passar dos anos, a Capes tem sido decisiva para os êxitos alcançados pelo Sistema Nacional de Pós-Graduação (SNPG), tanto no que diz respeito à consolidação do quadro atual como na construção das mudanças que o avanço do conhecimento e as demandas da sociedade exigem (COORDENAÇÃO DE APERFEIÇOAMENTO DE PESSOAL DE NÍVEL SUPERIOR, 2008).

Para cumprir sua missão, a Capes realiza uma série de atividades que podem ser agrupadas nas seguintes linhas de ação: 1) avaliação da pós-graduação stricto sensu; 2) acesso e divulgação da produção científica; 3 ) investimentos na formação de recursos de alto nível no país e exterior; 4) promoção da cooperação científica internacional; e 5) indução e fomento da formação inicial e continuada de professores para a educação básica nos formatos presencial e 
Ferraz et al. / Planejamento anual e quadrienal de prestação de contas à Capes por meio da ferramenta computacional Scriptsucupira

a distância (COORDENAÇÃO DE APERFEIÇOAMENTO DE PESSOAL DE NÍVEL SUPERIOR, 2008).

Para Maccari (2008), a implantação do sistema de avaliação em 1976, pela Capes, vem cumprindo papel importante para o desenvolvimento da pós-graduação e da pesquisa científica e tecnológica no Brasil. No desenvolvimento do sistema de avaliação da Capes, ao longo de mais de 30 anos, entende-se que seja necessária a especificação, com nitidez, da relação que se estabelece entre critérios científicos e objetivos sociais, bem como a forma de elaboração de conceitos, seu domínio de validade e que conclusões podem ser realmente sustentadas pela metodologia empregada. Adicionalmente, o sistema precisa ser calibrado entre as áreas, para que uma nota de uma determinada área represente a mesma nota em outra, obviamente respeitando-se as especificidades de cada uma.

Nessa linha, Gatti et al. (2003) afirmam que qualquer processo de avaliação só tem características científicas e sentido social quando estão bem definidos o contexto de referência e os objetivos. Ainda conforme Maccari (2008), a Capes tem contribuído para o desenvolvimento em quantidade e qualidade da pós-graduação stricto sensu, o que se nota com a proliferação dos cursos de mestrado e doutorado nos últimos anos e com a evolução nos indicadores de qualidade do seu sistema de avaliação.

O sistema de avaliação, continuamente aperfeiçoado, serve de instrumento para a comunidade universitária na busca de um padrão de excelência acadêmica para os mestrados e doutorados nacionais. Os resultados da avaliação servem de base para a formulação de políticas para a área de pós-graduação, bem como para o dimensionamento das ações de fomento - bolsas de estudo, auxílios e apoios (COORDENAÇÃO DE APERFEIÇOAMENTO DE PESSOAL DE NÍVEL SUPERIOR, 2008). O sistema de avaliação dos programas de pós-graduação compreende o acompanhamento anual, por meio dos dados inseridos na Plataforma Sucupira, e a avaliação quadrienal, a qual apresenta o desempenho de todos os programas e cursos integrantes do SNPG.

Os resultados dos acompanhamentos são expressos pela atribuição de conceitos na escala de 1 a 7 que fundamentam a deliberação do Conselho Nacional de Educação (CNE) do Ministério de Educação e Cultura (MEC) sobre quais cursos obterão a renovação de "reconhecimento" a vigorar no quadriênio subsequente. A rigor, o curso passa a integrar o SNPG quando obtém nota mínima igual a 3, sendo que os programas que atingirem conceitos "1" e "2" não são reconhecidos pelo MEC. Já os programas que obtiverem conceitos "6" e "7" são considerados de excelência internacional (LEITE; VIANA; PEREIRA, 2010).

Tais conceitos passam então a vigorar por todo o quadriênio seguinte, quando os programas serão novamente avaliados. Basicamente, a avaliação conduzida pela Capes leva em consideração quesitos como a proposta central do programa, o corpo docente, o corpo discente, a produção intelectual de seus pares e a sua inserção social.

\subsection{A Plataforma Lattes}

A Plataforma Lattes foi desenvolvida pelo Conselho Nacional de Desenvolvimento Científico e Tecnológico $(\mathrm{CNPq})$ com a finalidade de unificar o cadastro nacional de 
Ferraz et al. / Planejamento anual e quadrienal de prestação de contas à Capes por meio da ferramenta computacional Scriptsucupira

pesquisadores, assim propiciando uma integração com as principais agências responsáveis pela concessão de fomento para a pesquisa no país. Dessa forma, qualquer solicitação de recursos para pesquisa poderá utilizar as informações fornecidas à plataforma pelos próprios pesquisadores. Após a unificação do cadastro de pesquisadores em uma única base curricular, órgãos como o Ministério da Ciência, Tecnologia, Inovações e Comunicações, o CNPq, a Financiadora de Estudos e Projetos (Finep) e a Capes - além das Fundações de Amparo à Pesquisa (FAP) - obtêm fácil acesso ao histórico de pesquisa do solicitante, o que facilita as decisões relacionadas à concessão ou não de fomento para pesquisa. Isso, de certa forma, exige o cadastro e atualização periódica das informações constantes na Plataforma por toda a comunidade científica atuante no Brasil.

Em 2012, a Plataforma Lattes contava com mais de dois milhões de currículos cadastrados (ALVES; YANASSE; SOMA, 2012). Não são conhecidas até este momento bases curriculares únicas semelhantes à Plataforma Lattes. O que se tem disponíveis são bases de dados referenciais, das quais se pode extrair fontes de informação secundárias. O Brasil é o único país que vincula obrigatoriamente as informações constantes em uma plataforma curricular com as solicitações de fomento aos órgãos competentes para tal, com a concessão de bolsas e auxílios à pesquisa e também com a avaliação da qualidade dos cursos de pósgraduação stricto sensu.

Embora a Plataforma Lattes esteja, hoje, presente em diversos países da América Latina e também em Portugal, nesses países o preenchimento não é obrigatório e as informações disponíveis na Plataforma não são necessariamente utilizadas nas decisões de concessão de fomento.

A avaliação dos currículos cadastrados na Plataforma Lattes permite a obtenção de uma série de informações que não estão naturalmente disponíveis nas bases referenciais, ou seja, aquelas onde estão depositados os artigos científicos, as teses, as dissertações, os livros, dentre outras fontes de referências. No caso dos projetos submetidos - orientações realizadas e em andamento (que permitem realizar uma avaliação prospectiva dos futuros resultados das pesquisas vigentes), artigos publicados em jornais e revistas de grande circulação (que são indicadores da popularização dos resultados de pesquisas científicas), produtos, processos ou técnicas (que retratam o nível de responsabilidade social da pesquisa), além dos artigos aceitos para publicação, dentre outros -, estes só podem ser encontrados em bases não referenciais, como é o caso da Plataforma Lattes.

Além da possibilidade de avaliação dos indicadores listados, estes currículos constituem, portanto, uma fonte de informação não somente para análise individualizada, mas também para avaliação de redes sociais estabelecidas entre os pesquisadores (BALANCIERI et al., 2005), que consistem nas redes de colaboração em produção científica (MARTINS et al., 2013). Infelizmente, o CNPq não viabiliza o acesso em massa aos dados cadastrados nos currículos disponíveis na Plataforma Lattes, embora estes sejam documentos de consulta pública, o que obriga os pesquisadores que se dispõem a realizar estudos envolvendo análise de informação a depender, até este momento, da solicitação e liberação de dados pelo referido conselho (LEITE; MUGNAINI; LETA, 2011; MUGNAINI; LEITE; LETA, 2011). 
Ferraz et al. / Planejamento anual e quadrienal de prestação de contas à Capes por meio da ferramenta computacional Scriptsucupira

\subsection{O processo de preenchimento da Plataforma Sucupira}

Embora a Capes considere diversos indicadores tanto quantitativos quanto qualitativos no momento da avaliação dos programas stricto sensu, as atuações do corpo docente e do corpo discente impactam de forma decisiva na nota final que o programa irá receber. Dentre esses indicadores, sem dúvida, o desempenho do corpo docente é o de maior influência na avaliação de um programa, já que suas atividades geram impacto direto sobre a maioria dos outros indicadores envolvidos no sistema de avaliação da Capes (MACCARI; LIMA; RICCIO, 2010). Por exemplo, na área de Administração Pública e de Empresas, Ciências Contábeis e Turismo, a produção intelectual - um indicador de produtividade que contribui com 35\% da avaliação da Capes - é notadamente influenciada pelo desempenho do corpo docente durante o quadriênio. Como principal fator constituinte dessa produção, destaque deve ser dado à publicação bem distribuída de artigos em periódicos classificados no sistema Qualis Capes.

Segundo Nascimento (2010), todas as atividades realizadas pelos professores durante o quadriênio são valorizadas pela Capes. A formação dos docentes permanentes, a adequação da dimensão, a composição e dedicação dos docentes permanentes, o perfil do docente permanente com relação à proposta do programa, a atividade dos docentes permanentes na pós-graduação e na graduação, e a participação dos docentes em atividades de pesquisa e desenvolvimento contribuem para a boa avaliação geral de um curso.

Já com relação à atuação do corpo discente - indicador diretamente influenciado pelo desempenho dos docentes do programa -, considera-se especialmente a quantidade de teses e dissertações defendidas no período de avaliação com relação ao tamanho do corpo docente permanente e à dimensão do próprio corpo discente; as defesas das teses e dissertações do decorrer do quadriênio; a qualidade das teses e dissertações, além de outras produções científicas dos discentes, considerados autores da pós-graduação e da graduação; a eficiência do programa na condução do processo de formação dos mestres e doutores; participação dos discentes e dos egressos do programa em eventos alinhados à proposta do curso (MARTINS; MACCARI, 2015).

A alimentação da Plataforma Sucupira é realizada com informações provenientes de duas fontes de dados, uma interna e outra externa. A fonte de informação interna diz respeito ao sistema de back-office de cada programa. Esse sistema é composto pelas seguintes informações: dados cadastrais (docentes, discentes e egressos), proposta do programa, financiadores, linhas de pesquisa, projetos de pesquisa, disciplinas, turmas e trabalhos de conclusão. Já a fonte externa é composta por informações disponíveis na Plataforma Lattes e que permitem o acesso a uma série de dados dos docentes, discentes e egressos de um programa. As informações mais acessadas são aquelas referentes às produções científicas, técnicas e tecnológicas (MARTINS; MACCARI, 2015).

A coleta dessas informações exige atenção das secretarias dos programas, ocupando uma considerável parcela de tempo para sua execução. Qualquer informação esquecida ou preenchida de maneira inadequada poderá prejudicar a avaliação do programa, especialmente se tal fato ocorrer ao final do quadriênio, quando não há mais a possibilidade de correção e, efetivamente, os avaliadores da Capes emitirão a nota final após a obtenção de uma impressão 
Ferraz et al. / Planejamento anual e quadrienal de prestação de contas à Capes por meio da ferramenta computacional Scriptsucupira

geral sobre o curso (SCHERER et al., 2012). Em termos gerais, a Plataforma Sucupira permite maior transparência e confiabilidade nas informações fornecidas pelos programas, além de permitir gerar relatórios de desempenho, que serão utilizados para a atribuição das notas nas próximas avaliações quadrienais.

O processo de alimentação e transferência de dados para a Plataforma Sucupira é complexo, embora algumas informações possam ser extraídas de maneira automatizada, boa parte da alimentação da Plataforma é realizada de forma manual. Sendo assim, o desenvolvimento de ferramentas que contribuam para a automatização do referido processo poderia resultar em redução do tempo gasto e melhoria da qualidade das informações fornecidas, o que provavelmente refletiria na diminuição dos custos com pessoal e na dinamização do serviço das secretarias. Ainda, são notórias as dificuldades das coordenações dos programas de pós-graduação na realização de acompanhamento atualizado da produção individual dos docentes sob sua supervisão, ou mesmo na observação do panorama geral da produção científica do seu programa como um todo, dos cursos que o compõem ou das linhas de pesquisa que constituem esses cursos.

\subsection{Ferramentas de automatização de busca de currículos e produção acadêmica}

A literatura especializada relata a existência de três principais ferramentas capazes de extrair informações de diversas naturezas utilizando como universo os currículos depositados na Plataforma Lattes. São elas o Lattes Extrator, o Lattes Miner (ALVES; YANASSE; SOMA, 2012), e o Scriptlattes (MENA-CHALCO; CESAR JUNIOR, 2009).

O Lattes Extrator é uma ferramenta desenvolvida pelo próprio CNPq em que apenas instituições previamente cadastradas podem extrair da Plataforma Lattes informações relativas ao seu corpo docente, corpo discente e demais colaboradores, caracterizando-se, portanto, como uma ferramenta de uso restrito. O Lattes Miner é uma ferramenta automatizada, de domínio público, que pode ser utilizada para extração de informações da Plataforma Lattes com relação a alguns indicadores de desempenho dos docentes, pesquisadores, alunos e programas de pósgraduação (ALVES; YANASSE; SOMA, 2012). Já o Scriptlattes, além de ser uma ferramenta também de domínio público e que possibilita a extração da produção acadêmica de um determinado grupo de pesquisadores, também é capaz de gerar relatórios e gráficos, disponibilizando-os em páginas na web que podem ser facilmente acessadas não só pelos avaliadores da Capes ou pelos gestores dos cursos de pós-graduação, mas também por qualquer indivíduo interessado em acompanhar a evolução de um programa, de um curso, de uma linha de pesquisa, ou de um pesquisador em especial (MENA-CHALCO; CESAR JUNIOR, 2009).

\subsection{A ferramenta Scriptsucupira}

O Scriptsucupira é uma ferramenta computacional de uso livre que funciona em equipamentos pessoais por meio do ambiente Linux (visto que até este momento o ambiente Windows $^{\circledR}$ ainda não possui todas as bibliotecas necessárias para sua operação). De maneira resumida, o referido software, caracterizado como um programa-robô, é capaz de executar, 
Ferraz et al. / Planejamento anual e quadrienal de prestação de contas à Capes por meio da ferramenta computacional Scriptsucupira

simultaneamente, diversos Scriptlattes, com base em listas de alimentação fornecidas à ferramenta no formato de arquivos de configuração, descritas mais adiante. Cada Scriptlattes executado pelo Scriptsucupira é capaz de baixar os currículos Lattes de um grupo de pesquisadores cadastrados no $\mathrm{CNPq}$, extrair desses currículos as informações acadêmicas e profissionais necessárias, excluir produções redundantes e criar relatórios específicos que agrupem cada tipo de produção, dentre outras aplicabilidades, relativos à lista de pesquisadores fornecida à ferramenta (MENA-CHALCO; CESAR JUNIOR, 2009).

Ao executar simultaneamente os Scriptlattes, o que não era possível antes do seu desenvolvimento, o Scriptsucupira viabiliza a execução de alguns módulos computacionais tendo como base listas montadas manualmente pelas secretarias dos programas de pósgraduação. Essas listas devem contemplar os nomes dos pesquisadores, seus ID Lattes, além de outras informações, como as linhas de pesquisa e os cursos aos quais estes pesquisadores se encontram vinculados, se o docente é permanente ou colaborador, constituindo um arquivo com a extensão “. list”. As informações relacionadas aos dados que devem ser extraídos do currículo de cada pesquisador listado no arquivo anterior são fornecidas à ferramenta com base em um arquivo de configuração com a extensão “. config”. Cabe reforçar que ambos os arquivos devem ser fornecidos ao Scriptsucupira antes da execução dos procedimentos computacionais por ele realizados. Resumidamente, o funcionamento da ferramenta Scriptsucupira consiste na execução simultânea de vários Scriptlattes, de forma automatizada e sem a necessidade de intervenção do usuário durante a execução da ferramenta, sendo esta sua principal vantagem em relação à utilização do Scriptlattes isoladamente, pois executava apenas uma extração por vez (ALVES; SANTOS; SCHIMIT, 2016).

O primeiro módulo de funcionamento do Scriptlattes extrai diretamente da Plataforma Lattes os currículos que se deseja analisar. Em seguida, ocorre um pré-tratamento dos dados com base na análise de redundância das produções registradas pelos pesquisadores. Após isso, são gerados relatórios de produção bibliográfica, técnica e artística, além de um relatório de orientações acadêmicas. Tais informações são utilizadas pelo próprio Scriptsucupira para a confecção de páginas no formato HTML (linguagem de marcação de hipertexto utilizada para produzir páginas na web), que podem ser disponibilizadas em um endereço na internet.

Com base nas informações aqui descritas - especialmente aquelas relacionadas à necessidade de se compilar de maneira organizada as produções acadêmicas e tecnológicas dos professores de um programa de pós-graduação stricto sensu com vistas à alimentação da Plataforma Sucupira e também relativas ao acompanhamento pelos gestores da produtividade em pesquisa desses programas, dos cursos que os compõem, das linhas de pesquisa integrantes de cada curso e dos pesquisadores pertencentes a cada uma das linhas -, o objetivo central deste trabalho é demonstrar a utilização da ferramenta computacional Scriptsucupira para extração e disponibilização on-line da produção científica dos professores pertencentes a um programa de pós-graduação stricto sensu em Administração. 
Ferraz et al. / Planejamento anual e quadrienal de prestação de contas à Capes por meio da ferramenta computacional Scriptsucupira

\section{MÉTODO}

Este relato buscou compartilhar a experiência do uso de uma ferramenta computacional no âmbito da gestão de programas de pós-graduação, especialmente no tocante ao desempenho dos atores envolvidos nesses cursos, visando monitorar o cumprimento dos requisitos necessários ao processo de acompanhamento anual e a avaliação quadrienal. Não há, portanto, um problema de pesquisa específico a ser resolvido, senão a morosidade do processo de agrupamento das informações aqui descritas quando realizado de forma manual, tampouco se pretendeu realizar uma investigação de natureza teórica-empírica.

Os parágrafos seguintes fornecem uma breve descrição do mecanismo básico pelo qual a ferramenta Scriptsucupira realiza a montagem das páginas contendo as informações relacionadas à lista de pesquisadores previamente cadastrados na Plataforma Lattes, que inicialmente alimentaram a ferramenta. Por não se tratarem do foco principal deste trabalho, informações de ordem computacional mais detalhadas sobre o processo, assim como o passo a passo para a obtenção e replicação dos resultados aqui apresentados, poderão ser facilmente obtidas no trabalho original de Mena-Chalco e Cesar Junior (2009), que discorre sobre o Scriptlattes, e no trabalho de Alves, Santos e Schimit (2016), que descreve o Scriptsucupira.

Embora não seja possível coletar dados diretamente da Plataforma Lattes, já que esta se encontra alocada em uma região da internet sem acesso para robôs de busca comumente utilizados, uma série de procedimentos computacionais permite que as informações dos currículos sejam recuperadas com base em dados públicos disponibilizados pela própria plataforma. Cada pesquisador cadastrado na Plataforma Lattes possui um registro único constituído por um código de 16 algarismos, denominado ID Lattes, que dá acesso direto a uma página na web onde o currículo do referido pesquisador fica hospedado.

Para a análise da produção de um programa de pós-graduação, é necessário criar arquivos-texto que contenham as listas com os ID Lattes de todos os pesquisadores, professores, alunos, egressos, técnicos, entre outros, dos quais se queira extrair a produção. Para confeccionar tais listas, já se encontra disponível um módulo computacional, constituinte da lista de programas do Scriptsucupira, que é capaz de levantar automaticamente os ID Lattes dos pesquisadores listados com base apenas em seus nomes, contanto que estes sejam fornecidos exatamente da maneira que estão cadastrados na Plataforma Lattes. As listas de alimentação do Scriptsucupira podem ser criadas separadamente, dependendo do que se espera com a análise (lista completa de professores, de alunos, de componentes de um departamento, de um programa, de uma linha de pesquisa, listas para análise individual dos professores, dentre outros).

Após a criação das listas de alimentação, seis módulos sequenciais de funcionamento são responsáveis pelo processamento das informações solicitadas à ferramenta, que são extraídas diretamente da Plataforma Lattes. Os resultados do tratamento se constituem de vários relatórios no formato HTML (escolhido por ser um modelo de fácil visualização na internet), contendo as informações resumidas (quantitativas) com relação à produção bibliográfica, técnica e artística, bem como supervisões acadêmicas, todas relacionadas aos membros listados no arquivo de entrada. 
Ferraz et al. / Planejamento anual e quadrienal de prestação de contas à Capes por meio da ferramenta computacional Scriptsucupira

Basicamente, o primeiro módulo de funcionamento do programa é responsável pela realização do download dos currículos diretamente da Plataforma Lattes. Ele dedica atenção especial à extração de informações relacionadas à publicação de artigos em periódicos. $\mathrm{O}$ segundo módulo do processamento extrai da Plataforma Lattes informações com respeito ao endereço profissional, à lista de produções e à lista de supervisões em andamento e concluídas (limitadas ao intervalo de tempo fornecido à ferramenta), além de baixar também a fotografia do pesquisador listado, evidentemente se este a tiver fornecido à Plataforma Lattes. A seguir, o terceiro módulo inicia o tratamento das redundâncias, em que o programa identifica e exclui possíveis produções em duplicidade logo após o pré-processamento dos currículos. No quarto módulo, o Scriptsucupira gera as redes de colaboração entre os membros cujos nomes compunham a lista de alimentação do programa, com base em suas produções científicas de maior importância. No penúltimo módulo é gerado um mapa de geolocalização, quando solicitado, que toma por base o endereço informado pelos pesquisadores listados à Plataforma Lattes. Por fim, no sexto módulo, todos os relatórios (páginas da internet) são gerados, sendo eles relacionados às produções científicas, técnicas e tecnológicas, às orientações e às supervisões (em andamento e concluídas), todas separadas por tipo e por ano (em ordem cronológica inversa).

Para originar os resultados apresentados a seguir, foram montadas 13 listas contendo os nomes e os ID Lattes de todos os professores do programa de pós-graduação stricto sensu em Administração de uma universidade de caráter privado com sede no estado de São Paulo. Esse programa se divide em cinco outros programas de pós-graduação modalidade stricto sensu, sendo um acadêmico - contendo os cursos de mestrado e doutorado, denominado Programa de Pós-Graduação em Administração (PPGA) - e quatro programas de mestrado profissional. Além de uma visão geral da estrutura do programa, pretendeu-se nesta experimentação permitir a visualização da produção científica de cada um dos cursos que o compõem, além das linhas de pesquisa que constituem cada curso e, finalmente, permitir o acompanhamento individual de professores pertencentes a cada uma das linhas de pesquisa constituintes dos respectivos cursos, cujas produções científicas, técnicas e tecnológicas podem ser visualizadas separadamente e individualmente para os anos de 2013, 2014 e 2015, além do acumulado relativo ao quadriênio 2013-2016, até o momento de realização das extrações aqui demonstradas.

\section{RESULTADOS}

Após a finalização dos mecanismos de extração e tratamento dos currículos, o Scriptsucupira gera uma série de pastas contendo os arquivos relativos às listas com as produções dos pesquisadores listados. Essas pastas podem ser consultadas localmente no computador, onde se executou a ferramenta, ou podem ser transferidas para outros equipamentos, também para consulta local, ou mesmo podem ser enviadas e armazenadas em um servidor de internet, que fornecerá um endereço eletrônico a fim de que os interessados tenham acesso às páginas em HTML geradas a partir dos referidos arquivos, bastando para isso digitar o endereço eletrônico fornecido na janela de qualquer navegador de internet. 
Ferraz et al. / Planejamento anual e quadrienal de prestação de contas à Capes por meio da ferramenta computacional Scriptsucupira

Os resultados a seguir encontram-se demonstrados de forma a permitir uma visão geral sobre os tratamentos realizados pelo Scriptsucupira. Após demonstrar a página inicial, que dá acesso aos resultados acumulados de toda a produção científica do programa avaliado desde a sua fundação (Figura 1), elencou-se, na sequência, os resultados totais do mesmo programa relativos aos anos de 2013, 2014, 2015 e 2016, e ao quadriênio 2013-2016 (Figuras 2A e 2B), que são o foco deste trabalho. Em seguida, são disponibilizados os resultados dos mesmos períodos referentes a todos os professores pertencentes ao stricto sensu em Administração (Figuras 3A e 3B); depois, os resultados relativos apenas aos professores do PPGA (Figuras 4A e 4B), que é um dos componentes do stricto sensu como um todo; finalizando com os resultados relacionados à linha de pesquisa Estratégia, que compõe o PPGA. Ainda, foram disponibilizados os indicadores de produção de um único professor pertencente ao programa, escolhido aleatoriamente, para ilustrar a possibilidade de avaliação individual do desempenho docente.

A Figura 1 apresenta um panorama geral da página disponibilizada quando se acessa o endereço eletrônico de direcionamento ao servidor onde as pastas geradas pelo Scriptsucupira foram depositadas. Nela podem ser visualizados os links que dão acesso a diversas outras páginas contendo as listas totais e parciais (divididas por curso) da produção dos professores do programa de stricto sensu em Administração avaliado. Na parte inferior da Figura, nota-se uma pequena seta, inserida para indicar o link específico para acesso às informações que permitem organizar o planejamento anual relativo aos anos de 2013, 2014, 2015 e 2016, e o preenchimento quadrienal compreendendo o período 2013-2016. Ainda na Figura 1, é possível visualizar os links de acesso às produções acumuladas de todo o programa no período escolhido, dos cinco cursos stricto sensu que o compõem e dos professores e alunos vinculados a cada um desses cursos.

Vale destacar que as informações apresentadas na Figura 1 - como os links de acesso à produtividade do curso como um todo, dos programas que o compõem, bem como o agrupamento de professores, alunos em sua totalidade, de mestrado e doutorado, anos de avaliação e quadriênio, gerados automaticamente pelo Scriptsucupira - são definidas pelo próprio pesquisador no momento da confecção do arquivo de configuração, que é fornecido ao software antes de sua execução. Dessa forma, é possível retirar ou incluir novos indicadores com base no interesse específico de cada programa que se dispuser a replicar os resultados aqui demonstrados, bastando para tal alterar o arquivo de configuração que alimenta o software. 
Ferraz et al. / Planejamento anual e quadrienal de prestação de contas à Capes por meio da ferramenta computacional Scriptsucupira

\section{Figura 1 - Tela com os links de acesso às listas totais dos indicadores de produção dos professores avaliados, geradas com a utilização do Scriptsucupira}

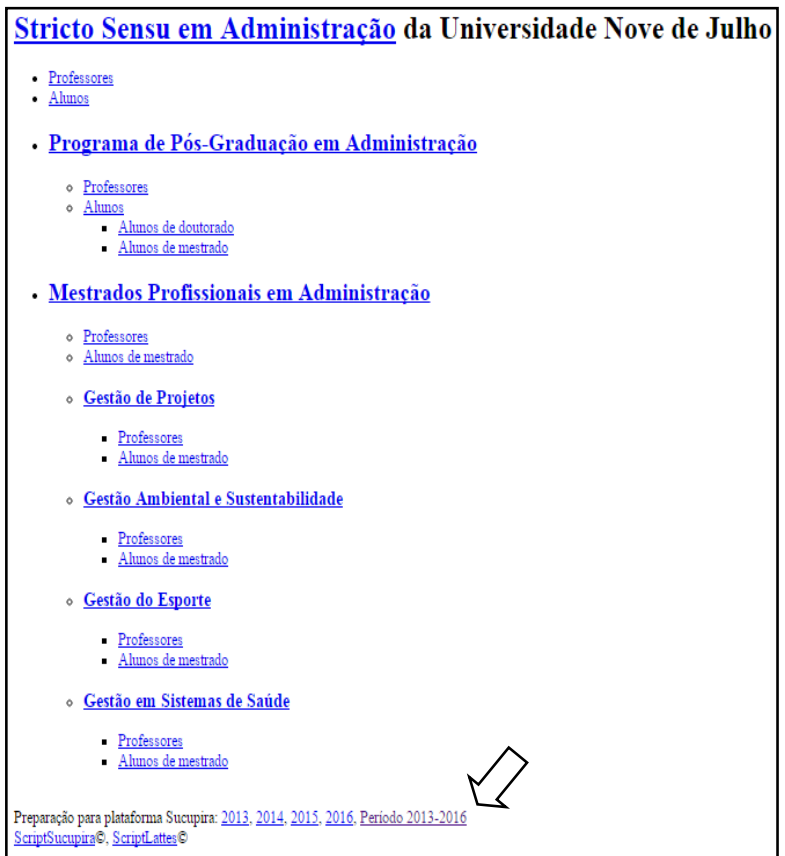

Fonte: Vlab4u - Grupo de Pesquisa em Ciência da Informação.

Legenda: A seta indica a posição dos links de acesso às produções de 2013, 2014 e 2015, e relativas ao quadriênio 2013-2016.

A Figura 2A traz como exemplo, à esquerda, a página disponibilizada imediatamente ao acessar o link "2016", presente na linha apontada pela seta na Figura 1, contendo vários links de acesso às produções científicas, relativas ao ano de 2016, cadastradas pelos pesquisadores na Plataforma Lattes até o dia em que os tratamentos descritos neste trabalho foram conduzidos. Já os links disponíveis à direita permitem acompanhar a produção científica acumulada dos quatro anos que constituem o quadriênio 2013-2016. O acesso às referidas informações permite aos gestores de cada programa acompanhar individualmente a produtividade em pesquisa não só dos cursos sob sua responsabilidade, mas também de cada uma das linhas de pesquisa que compõem estes cursos. Tais avaliações, se realizadas em tempo hábil, possibilitam a formulação de estratégias para alavancar a produção científica, por exemplo, de uma linha cuja produtividade esteja aquém das demais, evitando assim transtornos relacionados à falta de equidade entre as linhas, ou mesmo entre os cursos, no momento da avaliação dos programas pela Capes. 
Ferraz et al. / Planejamento anual e quadrienal de prestação de contas à Capes por meio da ferramenta computacional Scriptsucupira

Figura 2A - Telas relativas à preparação do preenchimento anual da Plataforma Sucupira para o ano de 2016 e para o quadriênio 2013-2016 (da esquerda para a direita)

\begin{tabular}{|c|c|}
\hline $\begin{array}{l}\text { Período } 2016 \\
\text { Stricto Sensu em Administracão }\end{array}$ & $\begin{array}{l}\text { Período 2013-2016 } \\
\text { Stricto Sensu em Administração }\end{array}$ \\
\hline - Programa de Pós-Graduacão em Administracão & - Programa de Pós-Graduacão em Administracão \\
\hline - OOrganizacōes e Empreendedorismo & ○ Organizacões e Empreendedorismo \\
\hline$\circ$ Marketing & $\circ \underline{\text { Marketing }}$ \\
\hline - Estratégia & ○ Estratégia \\
\hline - $\underline{\text { Inovacão }}$ & - $\underline{\text { Inovacão }}$ \\
\hline - Mestrados Profissionais em Administracão & - Mestrados Profissionais em Administracão \\
\hline - Gestão de Projetos & ○ Gestão de Projetos \\
\hline - Gerenciamento em Proietos & - Gerenciamento em Projetos \\
\hline - Estratégia em Projetos & - Estratéǵgia em Projetos \\
\hline - Gestão Ambiental e Sustentabilidade & ○ Gestão Ambiental e Sustentabilidade \\
\hline - Gerenciamento Ambiental & - Gerenciamento Ambiental \\
\hline - Gestão da Sustentabilidade & - Gestão da Sustentabilidade \\
\hline - Gestão do Esporte & - Gestão do Esporte \\
\hline - Marketing Esportivo & - Marketing Esportivo \\
\hline - Estratégia e Governanca no Esporte & - Estratégia e Gorernanca no Esporte \\
\hline - Gestão em Sistemas de Saúde & ○ Gestão em Sistemas de Saúde \\
\hline - Gestão em Saúde & - Gestão em Saúde \\
\hline - Gerenciamento em Sistemas de Saúde & - Gerenciamento em Sistemas de Saúde \\
\hline
\end{tabular}

Fonte: Vlab4u - Grupo de Pesquisa em Ciência da Informação.

Nota: é possível visualizar os links de acesso às produções científicas totais de cada um dos cursos que compõem o programa avaliado, ou às produções parciais divididas por linha de pesquisa.

Já a Figura 2B, que corresponde à parte inferior das mesmas páginas onde estão os conteúdos demonstrados na Figura 2A (que foi dividida apenas para facilitar a sua visualização), traz uma lista com os links contendo os nomes de alguns professores pertencentes ao programa avaliado. Quando acessados, esses links direcionam o usuário a novas páginas na web onde estão disponíveis as produções individuais dos anos de 2013, 2014, 2015 e 2016 ou do quadriênio 2013-2016, de cada um dos professores listados. Nesse caso, as produções de cada pesquisador serão disponibilizadas individualmente e em páginas separadas. A avaliação individual da produtividade de cada professor, assim como comentado em relação às linhas ou aos cursos, possibilita a tomada de decisão por parte dos gestores ainda na vigência do ano corrente, ou mesmo do quadriênio vigente, no intuito de garantir certo grau de equidade entre os professores do curso no quesito produtividade, o que por sua vez contribui positivamente na avaliação qualitativa do corpo docente conduzida pela coordenação. 
Ferraz et al. / Planejamento anual e quadrienal de prestação de contas à Capes por meio da ferramenta computacional Scriptsucupira

Figura 2B - Tela com a lista parcial dos professores pertencentes ao programa citado

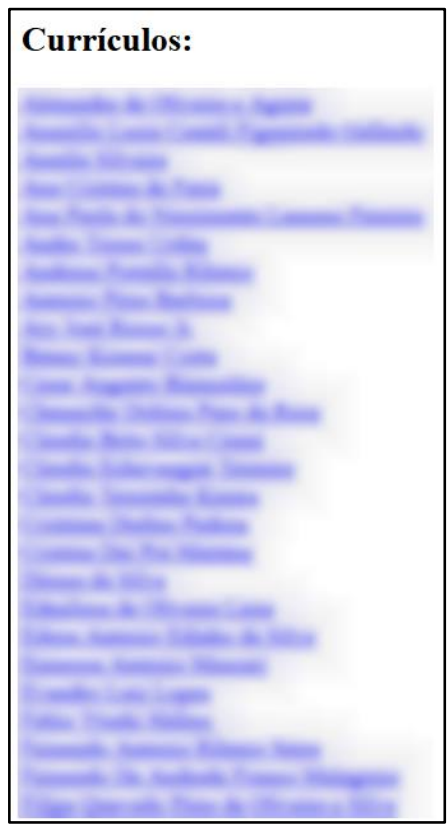

Fonte: Vlab4u - Grupo de Pesquisa em Ciência da Informação.

A Figura 3A apresenta as páginas contendo a produção científica de todos os professores pertencentes ao programa de stricto sensu em Administração avaliado. Tais páginas são acessadas ao clicar sobre o primeiro item disponível na parte superior das telas apresentadas na Figura 2A (link "Stricto Sensu em Administração"). Por exemplo, com relação aos artigos completos publicados em periódicos (primeiro link disponível à esquerda na Figura 3A), notase que em 2016 foram 252 publicações, o que resultou em um acumulado de 999 artigos publicados, soma esta disponível na tela representativa do quadriênio 2013-2016 (à direita).

Figura 3A - Links de acesso à produção bibliográfica, técnica e artística de todos os professores do programa avaliado, relativas ao ano de 2016 e ao quadriênio 2013-2016

\begin{tabular}{|c|c|}
\hline 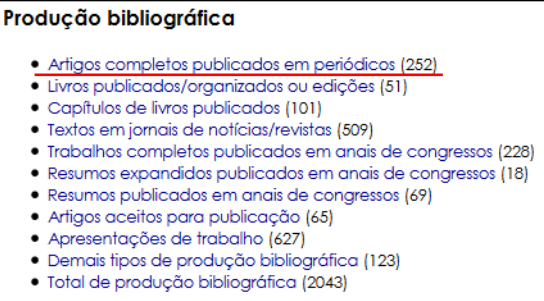 & 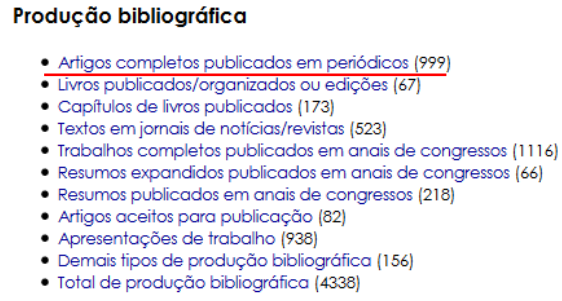 \\
\hline Produção técnica & Produção técnica \\
\hline $\begin{array}{l}\text { - Produtos tecnológicos (58) } \\
\text { - Processos ou técnicas (17) } \\
\text { - Trabalhos técnicos (4431) } \\
\text { - Demais tipos de produçáo técnica (1008) produção técnica (5514) }\end{array}$ & 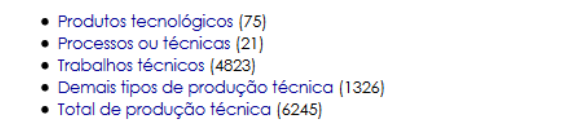 \\
\hline Produção artística & Produção artística \\
\hline - Total de produção artística (53) & - Total de produção artística (53) \\
\hline
\end{tabular}

Fonte: Vlab4u - Grupo de Pesquisa em Ciência da Informação. 
Ferraz et al. / Planejamento anual e quadrienal de prestação de contas à Capes por meio da ferramenta computacional Scriptsucupira

As orientações e supervisões, projetos de pesquisa, prêmios e títulos, participação e organização de eventos, além da data de construção dessas páginas, são apresentados na Figura 3B. É possível notar que, com relação aos prêmios e títulos, um foi recebido no ano de 2016 (à esquerda), resultando em um acumulado de 85 prêmios e títulos no quadriênio 2013-2016 (à direita).

Figura 3B - Links de acesso relativos ao ano de 2016 (à esquerda), e ao quadriênio 20132016 (à direita) de todos os pesquisadores do programa avaliado

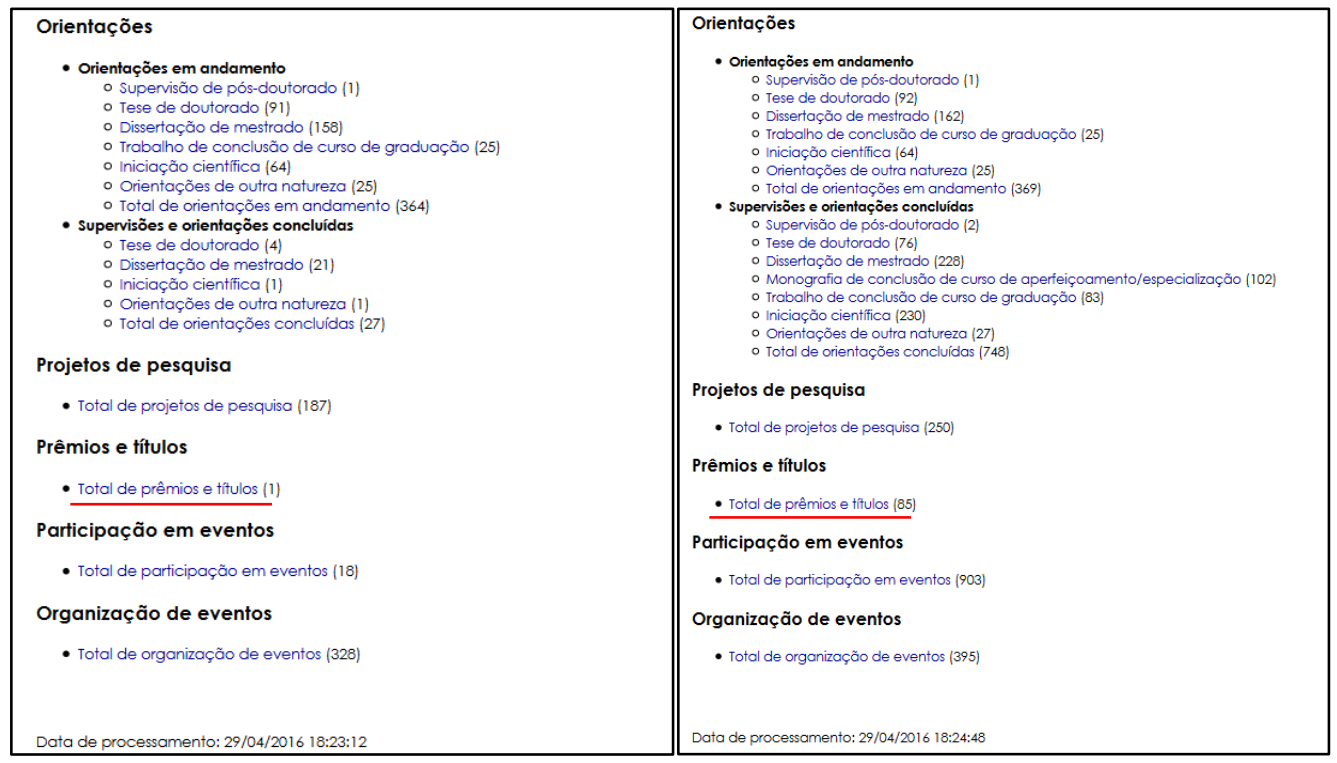

Fonte: Vlab4u - Grupo de Pesquisa em Ciência da Informação.

A Figura 4A apresenta as páginas onde estão contidos alguns dos links de acesso à produção bibliográfica e técnica de todos os professores do PPGA, um dos cursos que constituem o curso stricto sensu avaliado. Para ter acesso a tais telas, basta clicar sobre o segundo item disponível na parte superior das páginas apresentadas na Figura 2A (link "Programa de Pós-Graduação em Administração"). Como exemplo, com relação aos trabalhos completos publicados em anais de eventos, nota-se que em 2016 foram 156 publicações (à esquerda), contribuindo para um acumulado de 705 trabalhos no quadriênio 2013-2016 (à direita). 
Ferraz et al. / Planejamento anual e quadrienal de prestação de contas à Capes por meio da ferramenta computacional Scriptsucupira

Figura 4 - Parte superior da tela contendo os links de acesso à produção científica do ano de 2016 (à esquerda), e do quadriênio 2013-2016 (à direita)

\begin{tabular}{|c|c|}
\hline 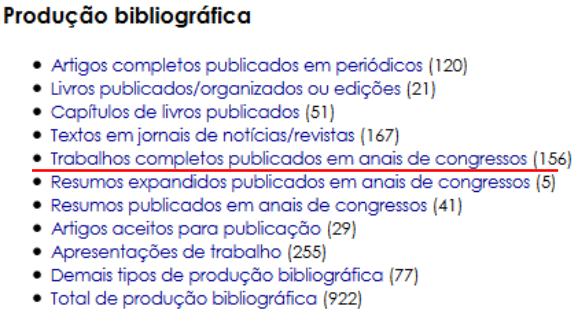 & $\begin{array}{l}\text { Produção bibliográfica } \\
\text { - Artigos completos publicados em periódicos (536) } \\
\text { - Livros publicados/organizados ov edições (30) } \\
\text { - Texplulos de livros publicados (97) } \\
\text { - Trabarnais de notícias/revistas (179) } \\
\text { - Resumos expandetos publicados em anais de congressos (705) } \\
\text { - Resumos publicados em anais de con anais de congressos (17) } \\
\text { - Artigos aceitos para publicação (38) } \\
\text { - Apresentações de trabalho }(396) \\
\text { - Demais tipos de produção bibliográfica (103) } \\
\text { - Total de produção bibliográfica (2181) }\end{array}$ \\
\hline $\begin{array}{l}\text { Produção técnica } \\
\text { - Produtos tecnológicos (45) } \\
\text { - Processos ou técnicas (4) } \\
\text { - Trabalhos técnicos (2630) } \\
\text { - Tomais tipos de produção técnica (543) } \\
\text { Todução técnica (3222) }\end{array}$ & $\begin{array}{l}\text { Produção técnica } \\
\text { - Produtos tecnológicos (47) } \\
\text { - Processos ou técnicas (6) } \\
\text { - Trabahos técnicos (2857) } \\
\text { - Demais tipos de produção técnica (602) } \\
\text { - Total de produção técnica (3512) }\end{array}$ \\
\hline $\begin{array}{l}\text { Produção artística } \\
\text { • Total de produção artística (5) }\end{array}$ & $\begin{array}{l}\text { Produção artística } \\
\text { - Total de produção artística (5) }\end{array}$ \\
\hline
\end{tabular}

Fonte: Vlab4u - Grupo de Pesquisa em Ciência da Informação.

A Figura 5A traz as telas em que é possível acessar as orientações de mestrado e doutorado, supervisões de pós-doutorado e projetos de pesquisa, tanto finalizados quanto em andamento, de todos os professores pertencentes à linha de pesquisa em Estratégia, que compõe o PPGA. Para acessá-las é necessário clicar sobre o terceiro link disponível na Figura 2A (link "Estratégia"). Como exemplo, com relação ao total de orientações concluídas, nota-se que em 2016 foram seis (à esquerda), totalizando 81 orientações concluídas, conforme pode ser visualizado na tela que representa o quadriênio 2013-2016 (à direita).

Figura 5 - Links de acesso às orientações e projetos de pesquisa dos professores pertencentes à linha de pesquisa em Estratégia, componente do PPGA

\begin{tabular}{|c|c|}
\hline 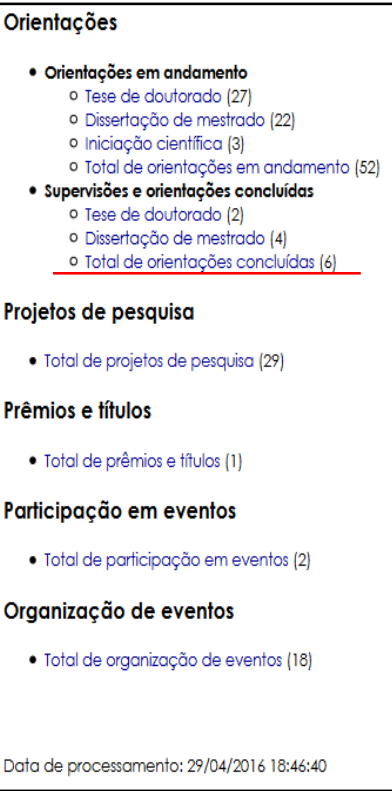 & $\begin{array}{l}\text { Orientações } \\
\text { - Orientações em andamento } \\
\text { o Tese de doutorado (27) } \\
\text { o Dissertação de mestrado (22) } \\
\text { o Iniciação cientfíca (3) } \\
\text { o Total de orientações em andamento (52) } \\
\text { - supervisões e orientações concluídas } \\
\text { o Tese de doutorado (18) } \\
\text { o Dissertação de mestrado (34) } \\
\text { o Trabalho de conclusão de curso de graduação (8) } \\
\text { o Iniciação cientifica (21) } \\
\text { o Total de orientações concluídas (81) } \\
\text { Projetos de pesquisa } \\
\text { - Total de projetos de pesquisa (39) } \\
\text { Prêmios e títulos } \\
\text { - Total de prêmios e tifulos (24) } \\
\text { Participação em eventos } \\
\text { - Total de participação em eventos (117) } \\
\text { Organização de eventos } \\
\text { - Total de organização de eventos (32) }\end{array}$ \\
\hline
\end{tabular}

Fonte: Vlab4u - Grupo de Pesquisa em Ciência da Informação. 
Ferraz et al. / Planejamento anual e quadrienal de prestação de contas à Capes por meio da ferramenta computacional Scriptsucupira

O Gráfico 1 mostra um detalhe da página ao clicar no link: Teses de doutorado, que é o quinto link disponível na parte superior de cada um dos dois quadros componentes da Figura 5. Neste exemplo, foram escolhidas apenas as orientações já finalizadas pelos professores da linha de pesquisa em Estratégia. É possível verificar a presença de uma barra representando as duas teses de doutorado defendidas no ano de 2016 (à esquerda), além do acumulado de 18 orientações de doutorado finalizadas no quadriênio 2013-2016 (à direita).

\section{Gráfico 1 - Representação gráfica das orientações de doutorado}

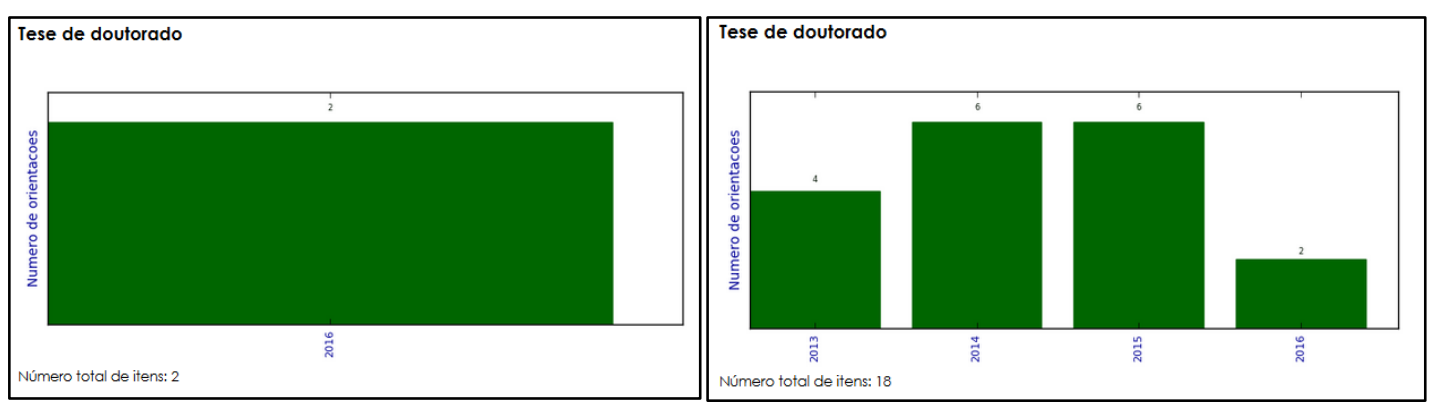

Fonte: Vlab4u - Grupo de Pesquisa em Ciência da Informação.

Por fim, a Figura 6 disponibiliza os links de acesso a todas as produções científicas do ano de 2016, além do acumulado de produções relativas ao quadriênio 2013-2016, de um professor pertencente à linha de pesquisa em Estratégia escolhido aleatoriamente. Para se ter acesso aos referidos links basta clicar no nome do professor listado na Figura 2B. Tomando-se como o exemplo o número de artigos completos publicados, observa-se que o referido professor publicou oito artigos completos no ano de 2016, totalizando 36 publicações no quadriênio 20132016. 
Ferraz et al. / Planejamento anual e quadrienal de prestação de contas à Capes por meio da ferramenta computacional Scriptsucupira

Figura 6 - Telas demonstrando os links de acesso à produção científica do ano de 2016 (à esquerda) e do acumulado referente ao quadriênio 2013-2016 (à direita)

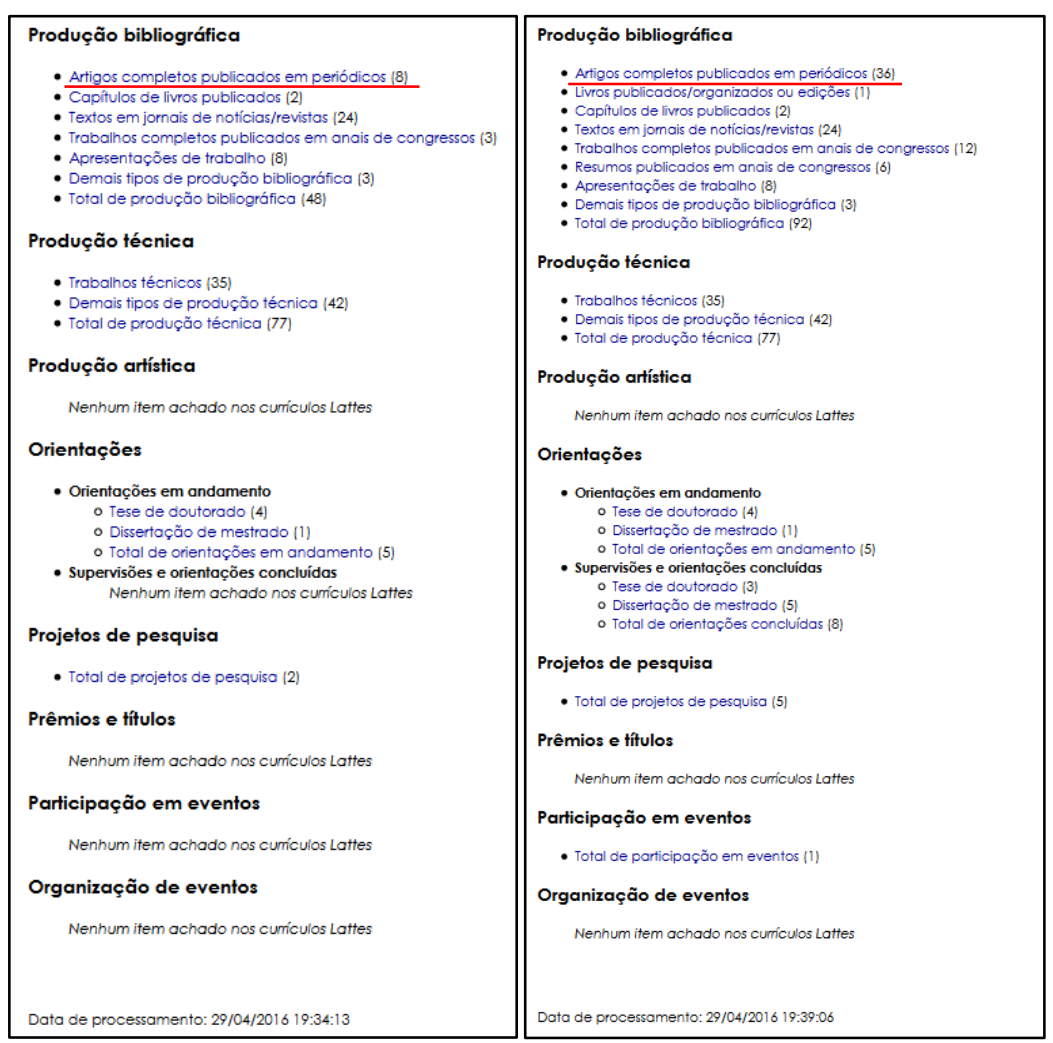

Fonte: Vlab4u - Grupo de Pesquisa em Ciência da Informação.

Caso deseje ter acesso à lista dos artigos publicados, bem como às bases de dados que hospedam as referidas obras, além do número de artigos enquadrados em cada um dos estratos da classificação Qualis na área de Administração, Ciências Contábeis e Turismo, basta clicar no link "Artigos completos publicados em periódicos", quando então se abrirão telas semelhantes às disponíveis no Gráfico 2. Na tela à esquerda, permite-se verificar que o professor utilizado como exemplo publicou, no ano de 2016, um artigo Qualis B1, um artigo Qualis B2 e um artigo Qualis C. No acumulado do quadriênio (à direita), nota-se que o mesmo professor possui seis publicações Qualis A2, duas publicações Qualis B1, sete publicações Qualis B2, quatro publicações Qualis B3, três publicações Qualis B4, quatro publicações Qualis B5 e duas publicações Qualis C. 
Ferraz et al. / Planejamento anual e quadrienal de prestação de contas à Capes por meio da ferramenta computacional Scriptsucupira

\section{Gráfico 2 - Número de publicações de um professor vinculado à linha de pesquisa em Estratégia}

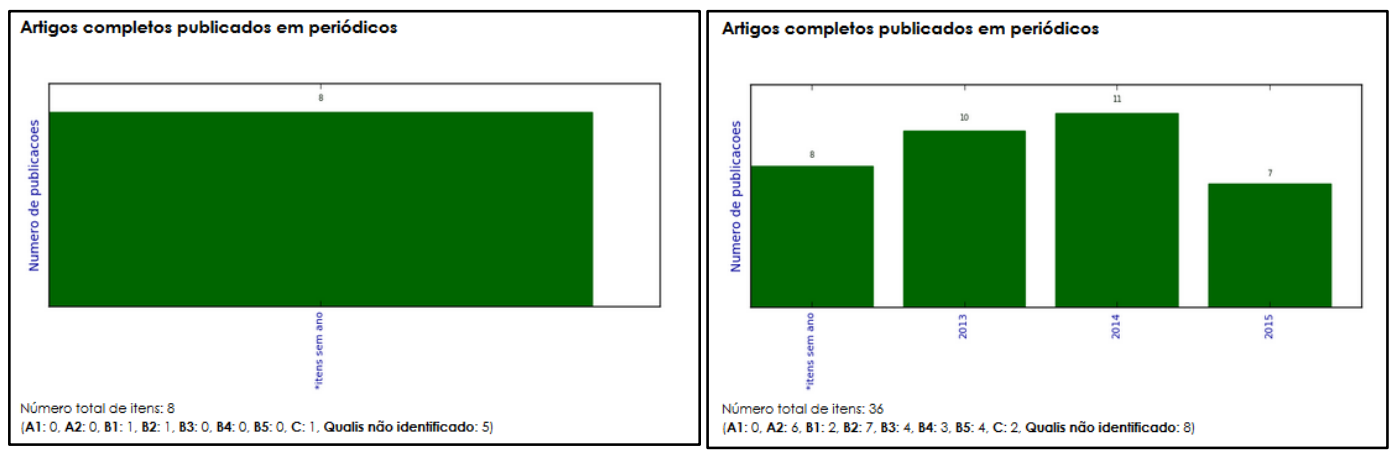

Fonte: Vlab4u - Grupo de Pesquisa em Ciência da Informação.

\section{CONSIDERAÇÕES FINAIS}

Neste relato de experiência, utilizou-se a ferramenta computacional Scriptsucupira como um programa-robô com o intuito de executar sequencialmente e de maneira automatizada o software Scriptlattes, sem a necessidade de acompanhamento ou intervenção do usuário, o que possibilitou extrair as produções científicas, técnicas e tecnológicas, além da atuação acadêmica de uma relação de professores pesquisadores pertencentes a um programa de pósgraduação stricto sensu em Administração. Os resultados apresentados demonstraram a eficácia da ferramenta no que tange à apresentação da informação de modo ordenado e em diferentes níveis de agregação, bem como à disponibilização dessas informações por meio de páginas de fácil acesso no formato HTML, trazendo à luz, de maneira organizada, uma série de dados outrora fragmentadas e disponíveis apenas individualmente nos currículos dos pesquisadores.

A oferta das informações aqui discutidas se mostra como uma ferramenta de gestão voltada ao planejamento anual e quadrienal do preenchimento da Plataforma Sucupira. Tais referências podem contribuir para o acompanhamento pelos gestores dos programas de pósgraduação do desempenho de seus professores individualmente, do desempenho das linhas de pesquisa, além de permitir a avaliação geral de cada um dos cursos e do programa como um todo. Destaca-se que a disponibilização das informações de forma transparente e de fácil acesso é realizada de maneira semelhante à sequência de itens observados pelas comissões de avaliação da Capes, facilitando o preenchimento, até o momento ainda não completamente automatizado, da Plataforma Sucupira, visto que a geração da listagem de resultados facilita a conferência de dados, o que por sua vez pode reduzir o tempo gasto nesse preenchimento, minimizar os erros no fornecimento de informações e, porventura, contribuir para o sucesso na avaliação e qualificação do programa.

Sugere-se que outras instituições que possuem programas de pós-graduação stricto sensu façam uso da ferramenta Scriptsucupira para: 1) tornar públicas as produções científicas de seus docentes, linhas de pesquisa, cursos e programas; 2) fornecer aos gestores dos programas stricto sensu a possibilidade de acompanhar periodicamente o desempenho dos cursos que estão sob sua gestão; 3) facilitar o agrupamento das informações que deverão ser acompanhadas anualmente e fornecidas quadrienalmente à Capes por meio do preenchimento 
Ferraz et al. / Planejamento anual e quadrienal de prestação de contas à Capes por meio da ferramenta computacional Scriptsucupira

da Plataforma Sucupira; 4) permitir que sejam formuladas estratégias buscando alavancar a produção científica de um curso, de uma linha de pesquisa, ou de um docente específico que, por algum motivo, não apresentem o desempenho esperado e adequado à proposta do programa em que estejam inseridos.

Finalmente, o uso da ferramenta Scriptsucupira proporciona aos gestores dos programas de pós-graduação stricto sensu a possibilidade de monitorar as atualizações dos currículos Lattes de cada um dos atores envolvidos na pós-graduação (docentes, discentes e egressos), haja vista que a qualidade das informações contidas na Plataforma Lattes tem grande influência na avaliação do desempenho geral do programa perante a avaliação da Capes. Vale mencionar que tanto os dados do Currículo Lattes quanto os dados inseridos na Plataforma Sucupira são declaratórios. Nesse sentido, apenas em casos de exceção haverá diligência por parte da Capes para verificação documental ou in loco das informações prestadas.

Dessa forma, a gestão dos programas de pós-graduação, no tocante ao processo de avaliação contínua baseado na fonte aqui apresentada, depende de como os dados são alimentados tanto pelos pesquisadores, no caso da Plataforma Lattes, quanto pelas secretarias, no caso da Plataforma Sucupira. Ignorar esse fato seria ignorar uma parte importante da questão, enfatizando apenas a funcionalidade de automatização realizada pelo Scriptsucupira. Assim, este relato não deve ser considerado apenas como uma via de divulgação das qualidades da ferramenta, mas sim do modo como estas qualidades facilitam o processo de lidar com os problemas de gestão relacionados aos cursos stricto sensu.

Com base nos relatórios disponibilizados pelo Scriptsucupira, os gestores de um departamento de pós-graduação podem, por exemplo, comparar a produtividade de dois diferentes programas de mestrado. Se esses programas possuem a mesma nota na avaliação Capes, espera-se que a produtividade dos programas seja, de certa forma, equitativa. No caso de um desses cursos apresentar, no cômputo geral, produção bibliográfica ou técnica muito aquém do planejado para o ano ou para o quadriênio, é possível remanejar professores, com base em suas expertises, para que estes contribuam na equalização da referida produtividade.

O remanejamento pode ser realizado com relação às linhas de pesquisa componentes de um mesmo programa, visto que uma produtividade equivalente entre elas pode contribuir positivamente no momento da avaliação pela coordenação. Ainda, a identificação de professores que por algum motivo apresentem indicadores de produtividade abaixo do esperado para o período, permite ao gestor a inclusão destes em novos grupos de pesquisa internos ou externos à instituição, para que pesquisadores possam estabelecer novas parcerias e alavancar a sua produtividade.

Ressalta-se que o acompanhamento aqui proposto pode ser realizado no momento em que o gestor desejar, bastando para isso executar, sempre que necessário, a ferramenta descrita neste relato de experiência. O monitoramento periódico dos indicadores de produtividade em pesquisa de professores, linhas de pesquisa e programas é, indubitavelmente, uma das principais estratégias não só para a busca de melhor conceito junto à Capes, mas também para manutenção de uma nota já conquistada, o que reflete a excelência do programa de pós-graduação em sua área de atuação. 
Ferraz et al. / Planejamento anual e quadrienal de prestação de contas à Capes por meio da ferramenta computacional Scriptsucupira

\section{Referências}

ALLEN, N. L. Avaliação em larga escala: lições de experiências. Brasília: Ministério da Educação e Cultura. SEDIAE: Fundação Cesgranrio, 1996. p.77-99.

ALVES, A. D.; YANASSE, H. H.; SOMA, N. Y. LattesMiner: uma linguagem de domínio específico para extração automática de informações da Plataforma Lattes. In: WORKSHOP DE COMPUTAÇÃO APLICADA, 12., 2012, São José dos Campos. Anais... São José dos Campos: Inpe, 2012.

ALVES, W. A. L.; SANTOS, S. D.; SCHIMIT, P. H. T. Hierarchical Clustering Based on Reports Generated by Scriptlattes. In Advances in Production Management Systems. Initiatives for a Sustainable World. Springer: Cham, 2016. p. 28-35.

BALANCIERI, R. et al. A análise de redes de colaboração científica sob as novas tecnologias de informação e comunicação: um estudo na Plataforma Lattes. Ciência da Informação, Brasília, DF, v. 34, n. 1, p. 64-77, 2005.

COORDENAÇÃO DE APERFEIÇOAMENTO DE PESSOAL DE NÍVEL SUPERIOR. História e Missão. Brasília, DF: Ministério da Educação, 2008. Disponível em: <https://goo.gl/28eURa>. Acesso em: 10 março. 2017.

. Plataforma Sucupira. Brasília, DF: Ministério da Educação, 2014. Disponível em: <https://goo.gl/UebXpC>. Acesso em: 10 março. 2017.

COSTA, J. S. B. Coleta, organização e divulgação da produção intelectual gerada na Universidade Federal do Rio Grande do Sul. In: SEMINÁRIO NACIONAL DE BIBLIOTECAS UNIVERSITÁRIAS, 9., 1996, Curitiba. Anais... Curitiba: UFP; PUC-PR, 1996.

DURHAM, E. R. A institucionalização da avaliação. Nupes: Núcleo de Pesquisas sobre Ensino Superior USP, São Paulo, v. 8, p. 1-15, 1990.

GATTI, B. et al. O modelo de avaliação da Capes. Revista Brasileira de Educação, Rio de Janeiro, n. 22, p. 137-144, 2003.

HOUSE, E. R. Tendencias en evaluación. Revista de Educación, Madrid, n. 299, p. 43-55, 1992.

LEITE, M. F. B.; VIANA, A. B. N.; PEREIRA, G. G. Métodos quantitativos na avalição da Capes: uma pesquisa bibliográfica. Facef pesquisa: desenvolvimento e gestão, Franca, v. 9, n. 2, p. 166-174, 2010.

LEITE, P.; MUGNAINI, R.; LETA, J. A new indicator for international visibility: exploring Brazilian scientific community. Scientometrics, Netherlands, v. 88, n. 1, p. 311-319, 2011. 
Ferraz et al. / Planejamento anual e quadrienal de prestação de contas à Capes por meio da ferramenta computacional Scriptsucupira

MACCARI, E. A. Contribuições à gestão dos programas de pós-graduação stricto sensu em administração no Brasil com base nos sistemas de avaliação norte americano e brasileiro. 2008. Tese (Doutorado em Administração) - Universidade de São Paulo, São Paulo, 2008 .

MACCARI, E.; LIMA, M. C.; RICCIO, E. L. Uso do sistema de avaliação da Capes por programas de pós-graduação em Administração no Brasil. Revista de Ciências da Administração, Florianópolis, v. 11, n. 25, p. 68-82, 2010.

MACCARI, E. A. et al. Sistema de avaliação da pós-graduação da Capes: pesquisa-ação em um programa de pós-graduação em Administração. Revista Brasileira de Pós-Graduação, Brasília, DF, v. 5, n. 9, p. 171-205, 2008.

MARTINS, C. B.; MACCARI, E. A. Desempenho dos programas de pós-graduação stricto sensu em Administração, Ciências Contábeis e Turismo no Brasil. Jundiaí: Paco, 2015.

MARTINS, C. B. et al. Influência das estratégias e recursos para o desenvolvimento dos programas de pós-graduação da área de Administração, Ciências Contábeis e Turismo no período de 2001 a 2009. Revista Gestão Universitária na América Latina: GUAL, Florianópolis, v. 6, n. 3, p. 146-168, 2013.

MENA-CHALCO, J. P.; CESAR JUNIOR, R. M. Scriptlattes: an open-source knowledge extraction system from the Lattes platform. Journal of the Brazilian Computer Society, London, v. 15, n. 4, p. 31-39, 2009.

MUGNAINI, R.; LEITE, P.; LETA, J. Fontes de informação para análise de internacionalização da produção científica brasileira. Ponto de Acesso, Salvador, v. 5, n. 3, p. 87-102, 2011.

NASCIMENTO, L. F. Modelo Capes de avaliação: quais as consequências para o triênio 20102012? Raep Administração: Ensino \& Pesquisa, São Leopoldo, v. 11, n. 4, p. 579-600, 2010.

OLIVEIRA, E. N. B. et al. Os programas de pós-graduação stricto sensu no contexto das avaliações Capes e CNPq. In: CONGRESSO NACIONAL DE EXCELÊNCIA EM GESTÃO, 4., 2008, Niterói. Anais... Niterói: Universidade Federal Fluminense, 2008.

OLIVEIRA, F. M.; TOTTI, M. E. F.; SOUZA, C. H. M. A web invisível e seus aspectos tecnológicos e sociais. In: CONGRESSO INTERNACIONAL INTERDISCIPLINAR EM SOCIAIS E HUMANIDADES, 2., 2013, Belo Horizonte. Anais... Belo Horizonte: Universidade Federal de Minas Gerais, 2013.

SCHERER, C. et al. Importância de um secretário executivo no preenchimento do aplicativo Coleta de Dados Capes. Revista de Gestão e Secretariado, São Paulo, v. 3, n. 1, p. 54-67, 2012. 
Ferraz et al. / Planejamento anual e quadrienal de prestação de contas à Capes por meio da ferramenta computacional Scriptsucupira

WALTER, S. A. et al. Oportunidades de melhoria nos programas de mestrado acadêmico em contabilidade a partir da avaliação da Capes: uma análise longitudinal. Avaliação: Revista da Avaliação da Educação Superior, Sorocaba, v. 18, n. 3, p. 567-589, 2013.

WILLIS, D. Educational assessment and accountability: a New Zealand case study. Journal of Education Policy, Abingdon, v. 7, n. 2, p. 205-221, 1992.

Recebido em 18/11/2016

Aprovado em 10/05/2017 